\title{
A ANALÍTICA DO PODER PASTORAL NA GENEALOGIA DAS ARTES DE GOVERNO EM FOUCAULT
}

\author{
Helrison Silva Costa ${ }^{1}$ \\ Universidade Federal de Minas Gerais (UFMG) \\ (iD) https://orcid.org/0000-0002-1061-3818 \\ E-mail: hcosta.fil@outlook.com
}

\section{RESUMO:}

No curso de 1978 Segurança, Território, População Foucault toma como objeto de análise o poder pastoral desenvolvido e ampliado pela Igreja Católica do século III ao século XVI. Como podemos situar esse estudo no percurso foucaultiano? Pensamos que a analítica do poder estendida ao âmbito pastoral serve à realização da genealogia da governamentalidade moderna, de modo que a arte de governar cristã é inserida no interior da história das práticas políticas racionalizadas. Procuramos demonstrar a tese do autor de que as técnicas empreendidas pela pastoral cristã produtoras de um poder ao mesmo tempo individualizante e totalizante se fazem presentes na governamentalidade política atual. Para isso, marcamos a especificidade do poder pastoral em relação à racionalidade política, o que confere sua exterioridade frente ao pensamento grego antigo e as artes de governo desde a modernidade. Assim, se evidencia a recusa de uma leitura laicizante do pastorado, pois as técnicas de governo pastoral ultrapassam o âmbito religioso em que estavam circunscritas, colocando a questão de como governar em diferentes campos sociais.

PALAVRAS-CHAVE: Foucault; Poder pastoral; genealogia; governamentalidade; Estado.

\section{THE ANALYSIS OF PASTORAL POWER IN THE GENEALOGY OF THE GOVERNEMENT ARTS IN FOUCAULT}

\begin{abstract}
:
In the course of 1978 Security, territory, Population Foucault takes as its object of analysis the pastoral power developed and extended by the Catholic Church from the third century to the 16th century. How can we place this study in Foucault's trajectory? We think that the analysis of power extended to the pastoral scope serves the realization of the genealogy of modern governmentality, so that the art of Christian government inserts itself in the history of rationalised political practices. We seek to demonstrate the author's thesis that the techniques undertaken by the Christian pastoral power and that produce a power at the same time individualizing and totalizing are present in current political governmentality. For that, we set the specificity of pastoral power in relation to political rationality, which confers its exteriority against the ancient Greek thought and the arts of government from the modernity. Thus, the refusal of a laicizing reading of pastorate is evident, since the techniques of pastoral government go beyond the religious sphere in which they were circumscribed, what puts the question of how to govern in different social fields.
\end{abstract}

KEYWORDS: Foucault; Pastoral power; Genealogy; Governmentality; State.

\footnotetext{
${ }^{1}$ Doutorando em Filosofia na Universidade Federal de Minas Gerais (UFMG), Belo Horizonte - MG, Brasil. Bolsita/CNPq.
}

COSTA, Helrison Silva. A analítica do poder pastoral na genealogia das artes de governo em Foucault. Griot : Revista de Filosofia, Amargosa - BA, v.18, n.2, p.421-434, dezembro, 2018. 


\section{A invenção das artes de governar no poder pastoral}

O interesse pela ampliação das práticas de governo é pautado sobre o arco de uma análise genealógica. No curso Sécurité, Territoire, Population Foucault assume como tarefa a realização de uma genealogia da governamentalidade. Isso implica em identificar historicamente os entrecruzamentos e redes que se ligaram para a formação das tecnologias governamentais. A perseguição desses acontecimentos coloca na genealogia das práticas de governo uma certa forma de condução de condutas desenvolvida e ampliada pelo cristianismo desde os seus primórdios, a partir do século III até o século XVI, a que Foucault se refere como poder pastoral.

O ponto de partida para a reflexão de Foucault acerca do pastorado consiste na constatação de que a ideia sobre a qual admite-se a possibilidade de se exercer um governo e de que os indivíduos são governáveis não provém do modo de vida grego. Para sustentar essa hipótese Foucault observa o lugar da metáfora do pastor no pensamento grego. A aposta do autor consiste na afirmação de que não obstante os gregos conhecerem o uso da metáfora do pastor, bem como a concepção de governo desdobrada a partir dela na forma de pastor-rebanho, a prática do poder pastoral não compõe a organização política grega. Fazendo referência a outras metáforas políticas, como a do rei assimilado a um timoneiro é observado que a própria ideia de governo dos homens está ausente da concepção política grega:

o objeto do governo, esse sobre o qual precisamente apoia-se o ato de governar, não são os indivíduos. $O$ capitão ou o piloto do navio, ele não governa os marinheiros, ele governa o navio. E do mesmo modo o rei governa a cidade, mas não os homens da cidade (FOUCAULT, 2004b, p. 127).

Portanto, a implementação de um poder pastoral pressupõe uma relação de poder em que aquilo que se governa é a conduta dos homens, condição ausente na Grécia Antiga. A esse tipo de organização política e de relação de poder de um governo sobre os homens Foucault localiza no lastro histórico que compreende o Oriente pré-cristão e a formação do Oriente cristianizado. A partir do aparecimento da metáfora do pastor com seu rebanho desdobra-se uma forma de relação em que alguns homens interferem na conduta de outros homens exercendo sobre eles uma direção de consciência.

A concepção em que o rei, o deus, o chefe aparece como um pastor de homens, responsável por conduzir seu rebanho à salvação é frequente em diversas tradições orientais como a egípcia, mas em especial a hebraica (FOUCAULT, 2004b, p. 149). Essa metáfora conforma uma relação entre o soberano e o Deus, de modo que ambos aparecem como o pastor dos homens, o primeiro enquanto um "pastor subalterno" que deve cuidar do rebanho neste mundo. Assim explica Foucault:

O faraó egípcio era um pastor. No dia de sua coroação, com efeito, ele recebia ritualmente o cajado de pastor; e o monarca da Babilônia tinha direito, entre outros títulos, àquele de 'pastor dos homens'. Mas Deus era também um pastor levando os homens ao seu pasto e provendo sua comida (FOUCAULT, 2001, p. 956). 
O que temos, então, é que o soberano na relação estabelecida pelo poder pastoral tem como tarefa conduzir a conduta dos homens que constituem o rebanho sob sua responsabilidade, "o rebanho que eles vigiam é o mesmo; o pastor real tem a guarda das criaturas do grande pastor divino" (FOUCAULT, 2001, p. 956). Essa relação do rei-pastor com suas ovelhas, contudo, é um traço que não caracteriza o poder pastoral desenvolvido pelos hebreus, cuja relação pastor-rebanho é "quase exclusivamente religiosa" ( ${ }^{1}$ FOUCAULT, 2004b, p. 149), quer dizer, apenas Deus era considerado pastor, que estabelecia uma relação com os homens.

Portanto, essa relação instituída entre Deus e os homens na forma de uma condução presente na relação pastor-rebanho é inteiramente estranha aos gregos. Não há nenhuma correspondência entre as tarefas desempenhadas pelos deuses gregos com a responsabilidade de guiar os homens como um pastor a seu rebanho, como se pode observar:

O deus grego funda a cidade, ele indica sua localização, ele ajuda na construção dos muros, ele garante a ela a solidez, ele dá seu nome à cidade, ele delega oráculos e por meio dele dá conselhos. Consulta-se o deus, ele protege, ele intervém, ele se zanga e se reconcilia, mas jamais o deus grego conduz os homens da cidade como um pastor conduziria suas ovelhas (FOUCAULT, 2004b, p. 129).

A partir disso Foucault vai examinar uma série de distinções entre o poder pastoral e o poder político na Antiguidade greco-romana. De início, o autor aponta que diferente do deus grego, o poder do pastor não se exerce sobre um território, pois os deuses gregos ocupavam a terra pertencente a eles. Ao contrário, o poder do Deuspastor incidia sobre o próprio rebanho, sobre uma "multiplicidade em movimento", cujo escopo é o de reunir, guiar e conduzir o rebanho, prezando pela unidade e ausência de conflitos. Assim:

Jamais a presença desse Deus hebraico é mais intensa, mais visível do que, precisamente, quando seu povo se desloca e quando, na errância do seu povo, em seu deslocamento, nesse movimento que o leva a deixar a cidade, as pradarias e as pastagens, ele toma a frente do seu povo e mostra a direção a qual se deve seguir (FOUCAULT, 2004b, p. 129).

Caracteriza-se assim uma relação de dependência com o dirigente. Além disso, o pastor exerce um "poder benfazejo", cujo escopo é conduzir o rebanho até a salvação, guiando-o por um caminho de abundância aonde o sustento necessário para sua caminhada é sempre garantido. Mais uma vez, essa característica está ausente da relação entre os gregos e seus deuses que de modo algum são responsáveis por prover os homens e lhes garantir bem-aventurança: "ao deus grego se pedia uma terra fecunda e de colheitas abundantes. Não se pedia a ele para sustentar um rebanho no dia-a-dia" (FOUCAULT, 2004b, p. 130).

O pastor tem, portanto, a obrigação de nutrir seu rebanho e isso ele o faz por meio de um zelo constante. Desse modo, "o pastor é aquele que vela", o que se traduz em um cuidado permanente com os outros: "o pastor está à serviço do rebanho, ele deve servir de intermediário entre ele e as pastagens, a comida, a salvação, isso implica em que o poder pastoral, em si, é sempre um bem" (FOUCAULT, 
2004b,p.132). Isso diz respeito à benevolência final, que é individualizada, dirigida a cada uma das ovelhas. Ora, o chefe grego devia pautar sua decisão no bem comum para não ser considerado um mau chefe. No entanto, aponta Foucault, sua tarefa era um "dever glorioso", pois mesmo que precisasse dar sua vida para a cidade recebia algo em troca. Por sua vez a benevolência pastoral se aproxima do "devotamento", tudo era feito única e exclusivamente para o bem do rebanho (FOUCAULT,2001, p. 959).

Portanto, são estes aspectos fundamentais que distinguem a prática pastoral surgido na Antiguidade do mundo grego: primeiro, o poder do pastor incide sobre os indivíduos e não sobre um território, sobre um rebanho em movimento; segundo, trata-se de um poder benfazejo que coloca como exclusiva finalidade de toda e qualquer ação do pastor o bem; terceiro, o escopo fundamental do pastor é guiar o rebanho (alma e corpo) à salvação, mesmo que para isso tenha que se sacrificar. Foucault define do seguinte modo o poder pastoral a partir dessas características:

\footnotetext{
É, portanto, um poder finalizado, um poder finalizado sobre aqueles mesmos sobre os quais se exerce e não sobre uma unidade de tipo, de certo modo, superior quer seja a cidade, o território, o Estado, o soberano. É um poder, enfim, que visa a todos e a cada um em sua paradoxal equivalência, e não a unidade superior formada pelo todo (FOUCAULT, M. 2004b, p. 133).
}

Diante disso, constata-se que Foucault atribui à antiguidade oriental a invenção da metáfora do pastorado que irá se desenvolver juntamente com o cristianismo de tal maneira que será impossível dissociar os dois processos, isto é, a cristandade se firma como pastorado. Assim, é possível afirmar que no pastorado cristão deu-se a invenção das artes de governo e da ideia de que os homens são governáveis. Diferentemente do pensamento político grego, a pastoral cristã exerce poder diretamente sobre os indivíduos por meio de tecnologias específicas que intervém sobre a conduta dos governados por meio da direção da consciência e um sistema de obediência, como veremos com maior detalhe à frente. Nessa seção cabe ressaltar a dimensão pulverizada de atuação dessa prática de governo e que constitui o traço fundamental do pastorado, justamente a ideia que substitui a unidade do território para multiplicidade de indivíduos que devem ser conduzidos a todos, com o propósito da salvação, mas sempre levando em conta as necessidades individuais de cada um.

\section{O lugar da metáfora do pastor na antiguidade grega}

Embora a metáfora do pastor-rebanho seja ausente da concepção política grega, não se pode afirmar que os gregos a ignoravam. Esse é o ponto apresentado por Foucault que examina de perto essa metáfora entre os gregos. Nesse percurso o francês acaba por identificar um conjunto de textos que denotam as circunstâncias em que essa metáfora aparece. Primeiramente, Foucault demonstra que a metáfora do pastor-rebanho está presente na literatura homérica e explica isso pela proximidade com a literatura assíria. Outro conjunto de textos em que essa metáfora se faz presente concerne à tradição pitagórica. Para Foucault, a relação entre o soberano e o pastor para os pitagóricos é inequívoca: eles identificam nomos (lei) 
como derivação de nomeus (pastor), haja vista que o pastor faz a lei enquanto administra os recursos do rebanho. Assim, concedem a Zeus o título de Nomios (deuspastor). Do mesmo modo, encontra-se nos pitagóricos a atribuição do magistrado como philanthropos, quer dizer como aquele que assume as prerrogativas do cargo visando unicamente o bem dos outros. Logo, proximidade com a função do pastor. No entanto, Foucault ressalta que apesar da coerência da tradição pitagórica, tratase ainda de uma presença marginal na cultura grega.

Por fim, o terceiro conjunto de textos em que se localiza a metáfora do pastor-rebanho concerne ao vocabulário político clássico. No entanto, as interpretações divergem acerca dessas passagens. Foucault apresenta a interpretação de Gruppe ${ }^{2}$, segundo a qual a metáfora do pastor é praticamente inexistente entre os gregos, tendo lugar apenas onde nota-se uma influência dos pitagóricos sendo, portanto, uma influência oriental. Por outro lado, Delatte ${ }^{3}$ argumenta que essa metáfora é central na Antiguidade grega e não se resume a uma influência pitagórica ou oriental, aparecendo com frequência no vocabulário político clássico. Sobre esse debate Foucault vai arbitrar em favor da leitura de Gruppe, argumentando que em Isocrátes a metáfora do pastor-rebanho e todo o vocabulário que ela mobiliza como poimém, nomeús não têm lugar no index isocrático. Mesmo quando o autor grego descreve as atribuições do magistrado, muito próximas à do pastor, a metáfora não aparece. Sendo assim, Foucault conclui que a metáfora do pastor no vocabulário político grego é incomum, mas com uma "exceção capital" em Platão.

No estudo que Foucault realiza do pastorado a referência ao tema do pastor aparece em diversos textos platônicos. No Crítias e no Político há uma designação dos deuses como pastores da humanidade. Nas Leis encontra-se uma designação do magistrado como sendo um pastor, um funcionário na forma de magistrado-pastor, o que significa que não cabe a ele a função do político de criação das leis, desempenhando um papel que Platão vai chamar de coadjuvante. Na República se coloca em discussão o tema do bom pastor ou do verdadeiro pastor que corresponde a uma figura ideal de magistrado. Mas é no Político em que se encontra uma análise esmiuçada e sistemática desse tema inquirindo acerca da possibilidade da política se constituir a partir da relação pastor-rebanho. Ora, é precisamente a constatação sobre a incongruência da relação pastor-rebanho na política, quer dizer, a nãocorrespondência entre o político com o pastor dos homens que sustenta a tese foucaultiana sobre a exterioridade da metáfora do pastor para a concepção política dos gregos. Sendo assim, a posição de Foucault se confirma pela rejeição de Platão à metáfora do pastor.

De acordo com Platão, não há conformidade entre o político e o pastor. Quando os homens eram guiados por um pastor esses eram os próprios deuses em um tempo que não é nosso, o qual justamente prescindia do político. Por sua vez, a política tem início a partir do término dessa era em que os deuses eram pastores dos homens, sendo que a figura do político que aparece em nosso tempo de modo algum pode corresponder à dos deuses no que concerne à tarefa de prover os homens. Assim,

\footnotetext{
2 Otto F. Gruppe foi um filósofo e filólogo alemão responsável por editar os fragmentos de Arquitas de Tarento. Ver STP, p. 160, n. 6.

3 Armand Delatte foi um helenista belga responsável por importantes estudos antigos, especialmente acerca dos pitagóricos. Ver STP, p. 160, n.7.
} 
a metáfora do pastor não se aplica a nenhum cargo político, pois o político é apenas um homem dentre outros homens. Há, portanto, uma exterioridade entre a função política e a função do pastor, sendo aquela melhor apreendida, para Platão, pela metáfora do tecelão. O político é em relação à arte de governar os homens na cidade como um tecelão que se ocupa da arte da tecelagem, apenas pode se efetivar contanto que haja o apoio de ações correlatas. Isso se distancia, portanto, do modo globalizante de atuação pressuposto pelo poder do pastor. $O$ tecelão tem uma atuação específica bem circunscrita em todo o processo de tecelagem. Do mesmo modo, o político como tecelão não tem como prerrogativa a execução de todas as tarefas que dizem respeito ao governo. A ação do homem político vai consistir em articular todas as atividades necessárias ao bom governo da cidade e que são desempenhadas por pessoas distintas nas figuras do médico, do pedagogo, do pai e mesmo a do pastor, não sendo possível identificar qualquer uma dessas atividades com a atividade do político. O político tecelão é aquele que conjuga a pluralidade de pessoas e atividades de modo a coexistirem em harmonia, formando uma comunidade política, a qual pode se constituir como Estado. A tarefa do político é a de "formar e assegurar a unidade da cidade", a partir do que Foucault conclui que: "o problema político é aquele da relação entre um e a multidão no quadro da cidade e de seus cidadãos" (FOUCAULT, 2001, p. 963).

Dessa identificação do político com a figura do tecelão Foucault percebe um movimento de recusa formal de Platão em relação ao tema do pastorado, não no sentido de eliminá-lo, mas de afirmar seu caráter de subordinação em relação à ordem política. A atividade do pastor não é aquela desempenhada pelo político, não obstante a sua importância particular para o bem da cidade ela está no mesmo nível das demais. Não se trata de promover a extinção dessa atividade, e sim, de deixá-la ao lado das outras, em sua especificidade. Por outro lado, não se trata também de poder atribuir ao homem político a prerrogativa de um pastor, a arte política não pode tomar como pressuposto o pastorado, pois este ainda que funcione em pequenas comunidades não poderia valer para toda a cidade, pois nessa escala o rei não seria capaz de realizar sozinho todas as atividades do pastor. Apenas um deus poderia exercer tal tarefa em uma escala global.

Portanto, encontra-se nos gregos não apenas uma ausência da metáfora do pastor como na exceção a isso, na análise platônica, encontra-se uma crítica explícita ao tema do pastorado. A partir disso, Foucault sustenta a afirmação de que a reflexão do pastorado não é exclusiva aos gregos, devendo ser localizada nos orientais e nos hebreus muito antes da Antiguidade. A aposta do autor é que a forma de organização pastoral se deu ao largo de uma reflexão política e de grandes organizações urbanas, no interior de pequenas comunidades filosóficas desenvolvidas sob a influência religiosa proveniente da Ásia e da África, bem como grupos dotados de socialidades específicas. Assim, Foucault acredita que para compreendermos como o tema do pastorado se difunde por toda a Grécia seria preciso empreender a análise das técnicas e reflexões utilizados por essas comunidades. Porém, com aquilo que temos historicamente o poder pastoral tem início com o processo de transformação de uma comunidade religiosa em Igreja, o que marca aquilo que viríamos a chamar de cristianismo. A Igreja se coloca como instituição "que pretende o governo dos homens de suas vidas cotidianas sob o pretexto de lhes conduzir à vida eterna em 
outro mundo" (FOUCAULT, 2004b, p. 151). Não de apenas alguns homens, mas de todos, em uma escala global. Para levar a cabo essa tarefa desenvolve ao longo de quinze séculos o poder pastoral.

É apenas com o cristianismo, com a instituição da Igreja, sua organização
hierárquica e territorial, mas também com o conjunto de crenças
concernentes ao além, ao pecado, à salvação, à economia do mérito, com a
definição do papel do padre que apareceu a concepção dos cristãos como
constituindo um rebanho, sobre o qual um certo número de indivíduos,
que gozavam de um estatuto particular, tem o direito e o dever de exercer
as incumbências do pastorado (FOUCAULT, 2001, p.548).

Contudo, a história dessa prática de poder, na perspectiva genealógica não estaria concluída, pois não pode ser circunscrita às transformações operadas pela Igreja. $\mathrm{O}$ autor observa que o poder pastoral emprega técnicas de individuação sobre os homens ao mesmo tempo em que investe sobre eles um poder totalizante. A isso Foucault se refere como o "paradoxo do pastor", quer dizer, ainda que o pastor guie o rebanho em sua totalidade "ele apenas pode dirigi-lo bem na medida em que não há uma só ovelha que lhe possa escapar", o pastor cuida de todo o rebanho e de cada ovelha em particular, o que é possível pela aplicação de técnicas, ao mesmo tempo, totalizantes e específicas, omnes et singulatim (FOUCAULT, 2004b, p. 132), de modo que o pastor "presta atenção a todos, sem perder de vista nenhum dentre eles. Ele é levado a conhecer seu rebanho no seu conjunto e no detalhe" (FOUCAULT, 2001, p. 958). Para Foucault, tais características perfazem as práticas de poder da modernidade no liberalismo e no neoliberalismo, por isso não podemos limitar a história das transformações concernentes às técnicas do poder pastoral àquelas operadas pela Igreja. "De fato, o poder pastoral em sua tipologia, em sua organização, em seu modo de funcionamento, o poder pastoral que se exerceu enquanto poder é sem dúvida algo de que nós não estamos, ainda, libertos" (FOUCAULT, 2004b, p. 152).

Essa marca do poder pastoral será o traço destacado por Foucault em suas análises. $O$ fato de que o poder pastoral exerça efeitos de individualização e totalização sobre os indivíduos que governa por meio de tecnologias específicas de poder é aquilo que será assimilado pelas tecnologias governamentais a partir do século XVI. Assim, o poder pastoral não apenas inaugura as artes de governo e desenvolve o pressuposto de que os homens são governáveis, como funda a ideia de que é preciso governa-los em todos os seus detalhes, aspectos e ações, um a um e, ao mesmo tempo, a todos, de modo que o governo se configura como uma dimensão à qual não se escapa.

De fato, a tecnologia de governo do pastorado inaugura um exercício de poder que procura atar os indivíduos a verdades que ele próprio enuncia sobre si mesmo. A isso corresponde a direção da consciência, conjugado a um sistema de obediência que mobiliza discursos de verdade para se fazer valer. Com efeito, os indivíduos são colocados em relações de subjetivação que conferem a eles identidades que interessam à manutenção das práticas de poder. Na modernidade essas práticas serão

${ }^{4} \mathrm{O}$ "paradoxo do pastor" refere-se ainda à forma sacrificial do pastorado em que o pastor, para salvar a vida de uma ovelha é capaz de sacrificar todo o rebanho e para salvar todo o rebanho sacrifica-se a si mesmo.

COSTA, Helrison Silva. A analítica do poder pastoral na genealogia das artes de governo em Foucault. Griot : Revista de Filosofia, Amargosa - BA, v.18, n.2, p.421-434, dezembro, 2018. 
conjugadas às práticas de normatização oriundas do poder disciplinar bem como às práticas de normalização oriundas de uma sociedade de regulação de modo que a obediência ao poder na contemporaneidade se dará como efeito do entrecruzamento desses modos de exercício do poder.

Desse modo, a partir da constatação de que as técnicas presentes no poder pastoral, elaboradas ao longo de séculos estão presentes ainda na prática política de nosso tempo é imprescindível tentar compreender algumas das transformações, embates e deslocamentos que possibilitaram a permanência do dispositivo pastoral nos arranjos das práticas políticas modernas ocidentais. No entanto, Foucault não tem como escopo a realização de uma história do poder pastoral, mas persegue historicamente pontos importantes dessa história na medida em que se cruzam com uma genealogia da governamentalidade.

\section{A especificidade do poder pastoral}

Ao analisar o poder pastoral Foucault destaca o caráter racionalizado dessa arte de governar, cuja reflexão alcançou um valor correspondente ao que era ofertado à filosofia até então, como vê-se pela definição do poder pastoral no século III como techné technôn (arte das artes), epistemè epistemôn (ciência das ciências), ideia que atravessa toda cristandade até o século XVIII de modo que a ars artium (arte das artes) será identificada com o regimen animarum (governo das almas). Ou seja, a arte acima de todas as outras é "a arte pela qual se ensina a governar os outros, ou pela qual se ensina a se deixar governar por alguns" (FOUCAULT, 2004b, p. 154). Foucault identifica que é a reflexão sobre esse tema do pastorado, e não a teologia, que paulatinamente toma o lugar da reflexão filosófica. Em razão disso, o pastorado no interior da formação da Igreja cristã se desprende de outras configurações em que se estabelece uma relação de Deus com os homens. Isso significa dizer que o poder pastoral se autonomiza e se coloca como relação fundamental que envolve todas as outras, de modo que vai se institucionalizar, arregimentando suas próprias leis, regras, técnicas e procedimentos.

\footnotetext{
Deve-se distinguir entre dois aspectos do poder pastoral: a institucionalização eclesiástica, que desapareceu, ou ao menos perdeu seu vigor desde o século XVIII, e a função dessa institucionalização, que foi estendida e desenvolvida fora da instituição eclesiástica (FOUCAULT, 2001, p. 1049).
}

Com isso, toda organização da Igreja teve como base a relação pastor-rebanho e todo poder da Igreja foi "organizado e justificado como poder do pastor em relação ao rebanho" (FOUCAULT, 2004b p. 157). Nota-se a dimensão englobante quanto à institucionalização dessa prática de poder, mas que é ao mesmo tempo específica, pois se o poder pastoral se estende e abarca todas as relações da Igreja, cria também mecanismos para que a relação do pastor-rebanho seja mantida a cada uma das ovelhas individualmente. Assim, diferentemente do pastorado judeu que apenas concebia Deus como pastor, o pastorado cristão irá designar como pastor uma série de integrantes da hierarquia eclesiástica. 
Outro aspecto que assinala o caráter singular do poder pastoral concerne à exterioridade que este mantém em relação ao poder político. Como pudemos observar, na análise do poder pastoral na Antiguidade há registros de uma reflexão política entre os gregos. Desse modo, o que existe é uma distinção radical entre o poder pastoral e o poder político no Ocidente que permanece mesmo ao longo das transformações e deslocamentos sofridos pelo pastorado, ao menos até o século XVIII. No entanto, isso não implica em um estranhamento da tarefa da Igreja quanto à dimensão terrena de sua tarefa de condução das almas dos indivíduos. Assim, o poder pastoral engendra, conforme Foucault, um paradoxo, pois:

\footnotetext{
Ele só se ocupa das almas dos indivíduos na medida em que esta conduta das almas implica também em uma intervenção, e uma intervenção permanente na conduta cotidiana, na gestão das vidas, mas também nos bens, nas riquezas, nas coisas (FOUCAULT, 2004b p. 157).
}

Do mesmo modo, afirmar a distinção entre o poder pastoral e o poder político não significa recusar os entrecruzamentos múltiplos que se deram historicamente, e sim considerar que não obstante essas interferências, "o poder pastoral vai permanecer absolutamente específico e diferente do poder político". Com isso Foucault afirma que "a distinção, a heterogeneidade do pastorado crístico e da soberania imperial, essa heterogeneidade me parece ser um dos traços do Ocidente" (FOUCAULT, 2004b p. 157). Mesmo que se atribua ao soberano funções religiosas, ele não substitui a figura do pastor, uma é irredutível à outra de modo que o poder do soberano coexiste com o do pastor. No entanto, quando se examina a história dos entrecruzamentos desses poderes no Oriente não se percebe a mesma heterogeneidade. Foucault demonstra seu ponto de vista citando o exemplo do que ocorreu no Império Russo, em que as figuras do soberano político se confundem com a do pastor, constituindo uma figura circunscrita ao Oriente de um "soberano crístico".

Além da heterogeneidade entre o poder pastoral que incide sobre a conduta dos homens guiando-os material e espiritualmente e o poder político que tem como escopo submeter os homens à lei e ao soberano, Foucault aponta ainda a irredutibilidade dessa prática a um poder pedagógico para formar os jovens e um poder retórico para convencer os homens. Assim, nosso autor constata que: "O pastorado não coincide nem com uma política, nem com uma pedagogia, nem com uma retórica. É alguma coisa inteiramente diferente" (FOUCAULT, 2004b, p. 169). A especificidade do poder pastoral consiste em sua configuração como arte de governar os homens que implica em uma série de deslocamentos em relação a um conjunto de temas comuns ao mundo Antigo.

\section{O poder pastoral e a governamentalidade moderna}

Como já referimos, o interesse de Foucault pelo pastorado se justifica pelo fato de que para o funcionamento dessa prática de poder desenvolvida pela Igreja com o propósito de conduzir a conduta dos homens formulou-se um conjunto de técnicas de governo, cujo efeito garante a individualização dos sujeitos, fazendo com que eles reconheçam modos de subjetivação fixados às práticas de poder 
assujeitadoras. Segundo o autor, tais técnicas mobilizadas pelo dispositivo pastoral durante quinze séculos, sem, contudo, deixar de sofrer deslocamentos e transformações diversos, chegam até a modernidade e integram as práticas políticas racionalizadas no início da modernidade e por isso estão na genealogia da governamentalidade.

\begin{abstract}
A pastoral cristã me parece ser o plano de fundo desse processo, estando bem entendido que há, de um lado, uma distância imensa entre o tema hebraico do pastor e a pastoral cristã e que terá, é claro, um outro desvio, não menos importante, não menos amplo entre o governo, a direção pastoral dos indivíduos e das comunidades e o desenvolvimento das artes de governar, a especificação de um campo de intervenção política a partir do século XVI-XVII (FOUCAULT, 2004b,p. 169).
\end{abstract}

Foucault percebe o poder pastoral como uma prática política incipiente, mas que foi capaz de uma intensa penetração nas relações de poder na sociedade, enquanto um exercício de condução operado por uns sobre a conduta dos outros. É precisamente a crise do poder pastoral, colocada pelas contracondutas religiosas, que altera as relações de poder desse dispositivo e engendram a multiplicação das artes de governo na modernidade, a partir de uma preocupação crescente sobre como governar. Por isso, o lugar privilegiado para se perceber as transformações em torno do pastorado é em meios às lutas travadas contra essa prática de poder, cujo ápice se deu na Reforma e na Contrarreforma. Durante o século XIII ao XVIII verifica-se uma "batalha da pastoralidade", cujo intuito é definir os responsáveis pelo governo dos homens, aqueles que fariam funcionar as técnicas do dispositivo pastoral e demarcariam seus limites de atuação.

Com efeito, as batalhas em torno do poder pastoral ao invés de promover o desaparecimento dessa prática política promoveram seu fortalecimento, pois "questionam o modo de governo pastoral, mas não o governo pastoral". No lugar da suplantação do poder pastoral as batalhas em torno dele tiveram como efeito uma intensificação maior das práticas de condução de condutas, tanto em sua forma protestante quanto católica, que provocaram um profundo rearranjo do dispositivo pastoral, como observa Candiotto: "Na dimensão espiritual, ocorre majoração das condutas de devoção, dos controles espirituais, da relação entre fiéis e seus pastores; quanto à extensão material, assume outros âmbitos tais como a propriedade, a educação das crianças" (CANDIOTTO, 2010, p. 110). Nas seitas protestantes desenvolve-se um pastorado meticuloso embora hierarquicamente flexível, já na Igreja Católica ocorre um acirramento das práticas pastorais e o enrijecimento das estruturas hierárquicas. Com efeito, evidencia-se e assume maior proporção o problema da condução de condutas, a partir do que se desenvolverá práticas de governo em âmbitos diversos da sociedade.

Não houve passagem do pastorado religioso à outras formas de conduta, de condução, de direção. Houve, de fato, intensificação, multiplicação, proliferação geral dessa questão e de suas técnicas de conduta. Com o século XVI entra-se na era das condutas, na era das direções, na era dos governos (FOUCAULT, 2004b, p. 236).

COSTA, Helrison Silva. A analítica do poder pastoral na genealogia das artes de governo em Foucault. Griot : 
A respeito disso Büttgen sustenta o argumento de que Foucault trata o desdobramento do poder pastoral na governamentalidade como uma intensificação em torno da problematização geral das condutas e passa ao largo da perspectiva comum de filósofos e historiadores que entendem a virada do mundo moderno como um amplo processo de secularização. Assim, Foucault não entende que o poder pastoral por ter se desenvolvido no âmbito religioso se identificasse com o poder eclesiástico e que ao adentrar à governamentalidade tivesse sido transformado em um poder político. Não se trata de pensar "que as formas modernas dos governos dos homens constituiriam então versões secularizadas do poder pastoral, nas quais o religioso ao mesmo tempo se eliminaria e se transformaria" (BÜTTGEN, 2007, p. 1137). Nota-se que Foucault evita pensar em termos de secularização e por isso se refere ao poder pastoral como "prelúdio", "esboço" ou "modelo arcaico" da governamentalidade, de modo que: "existe uma linha direta de herança religando o Estado e as governamentalidades modernas a um poder pastoral que se constitui como precursor, o ancestral, a pré-história delas" (FOUCAULT, 2004b, p. 236). Isso significa que Foucault confronta o esquema dual de uma passagem do teológico para o político e percebe o deslocamento das técnicas pastorais de uma utilização pela Igreja católica à utilização das práticas políticas, conservando a especificidade das técnicas pastorais quanto à condução de conduta nas relações de poder.

Podemos dizer, então, que a prática de poder pastoral se desdobra nos jogos de poder da atualidade e nas práticas governamentais que as fazem funcionar. Desse modo, Foucault afirma que no período que compreende o início da modernidade "assistiu-se a toda uma reconversão, a toda uma transplantação disso que tinha sido os objetivos tradicionais do pastorado" (FOUCAULT, 2004b, p. 350), fazendo com que as técnicas dessa prática política fossem arregimentadas no funcionamento do Estado. Com efeito, tal como no pastorado, as práticas governamentais no interior do Estado atuam de modo ao mesmo tempo globalizante e individualizante, tomando cada sujeito em sua singularidade, mas visando os aspectos globais observados pela população. Foucault se coloca contrário à tese comum de que a máquina estatal é alheia ao indivíduo, de que o grau de autonomia por ela adquirido a faz prescindir de pensar as necessidades e considerar as características dos indivíduos ${ }^{5}$.

Podemos perceber a insistência dada por Foucault quanto à afirmação da especificidade do poder pastoral. Na opinião do genealogista, ele não se identifica com nenhum outro tipo de poder. A partir disso Foucault concebe o desdobramento do poder pastoral nas práticas políticas modernas imprimindo lutas que são do mesmo modo específicas, de modo que Foucault recusa tratar o processo de governamentalização em termos de secularização, como é evidente:

\footnotetext{
${ }^{5}$ Em primeiro lugar Foucault aponta para uma "mudança de objetivo" do poder pastoral passa ser assegurar a salvação nesse mundo. Nesses termos, salvação passa a designar saúde, bem-estar (nível de vida correto, recursos suficientes), segurança, proteção contra acidentes, ou seja, um conjunto de "objetivos terrestres" que tomam o lugar do aspecto espiritual do pastorado de modo que Foucault liga o papel social da medicina à manutenção da Igreja católica e protestante. Segundo, ocorre um "reforço da administração" do poder pastoral que passa a ser exercido por um aparelho de Estado ou pela polícia que tem a função de garantir as condições salutares e o desenvolvimento do comércio. Esse poder também passa a ser exercido por meio de filantropia e, além disso, a família passa a integrar essa função. Terceiro, a multiplicação de objetivos conjugada à propagação de agentes no poder pastoral reforçam esse dispositivo como uma prática globalizante concernente à população e como uma prática analítica, concernente ao indivíduo.
}

COSTA, Helrison Silva. A analítica do poder pastoral na genealogia das artes de governo em Foucault. Griot : Revista de Filosofia, Amargosa - BA, v.18, n.2, p.421-434, dezembro, 2018. 
Eu não quero dizer que essa arte de governar os homens, sobre a qual eu tentei vos indicar alguns traços a propósito da prática pastoral, se tornou por um processo de simples transporte, transferência, translação, um dos atributos do poder soberano. Não é o rei que se tornaria pastor, que se tornaria pastor dos corpos e das vidas [...] é uma arte absolutamente específica de governar, uma arte que tinha nela mesma sua própria razão, sua própria racionalidade, sua própria ratio (FOUCAULT, 2004b, p. 293).

Vê-se o alastramento da prática pastoral na disseminação das práticas de governo que Foucault estende até a atuação do Estado. No lugar de encetar uma análise institucionalizada do Estado para tentar ver os modos de atuação, Foucault parte das relações governamentais e as faz avançar até o Estado. Assim, quando coloca sua tese de que as técnicas pastorais existem nas formas governamentais não prescinde ver como isso se dá em relação ao Estado, que como vimos, mobiliza práticas de individuação e incide sobre a conduta dos indivíduos em todos os aspectos da vida.

Portanto, guardados os devidos aspectos as tecnologias cristãs para condução de conduta que provocam o assujeitamento dos governados por meio de um processo de subjetivação individualizante e totalizante se encontram na base das práticas de governo racionalizadas que se exercem nas práticas de poder que compõem o Estado, de modo que apesar dos deslocamentos diversos encontrados entre a prática pastoral e a governamentalidade moderna permanece o escopo de conduzir a conduta dos indivíduos, de exercer sobre eles um governo por meio de dispositivos que produzam uma subjetividade determinada que interessa à adesão dos sujeitos às práticas de poder.

\section{Considerações Finais}

Ainda nas primeiras aulas do curso Sécurité, Territoire, Population, logo após anunciar a pretensão de empreender uma "história da governamentalidade" (FOUCAULT, 2004b, p. 111), Foucault inicia uma esmiuçada análise das práticas do poder pastoral, demonstrando a importância fulcral das tecnologias cristãs para compreensão das técnicas políticas da atualidade. Podemos entender que nesse curso ocorre o deslocamento nos estudos foucaultianos de uma analítica do poder iniciada na década de 60 até as análises concernentes à governamentalidade, como discutimos no capítulo precedente. Retomamos rapidamente essa discussão apenas para assinalar o contexto em que os estudos sobre o poder pastoral são empreendidos. Pensamos que a inflexão operada por Foucault no curso de 78 não configura uma ruptura da governamentalidade em relação aos estudos anteriores da analítica do poder. Trata-se de uma ampliação em que, conforme Büttgen observa no artigo Théologie politique et pouvoir pastoral: "o estudo dos dispositivos de poder descobre um novo campo de investigação" (BÜTTGEN, p. 2007, p. 1129). Assim, Foucault teria passado de uma análise do dispositivo disciplinar, do dispositivo da sexualidade na analítica do poder para uma análise do dispositivo pastoral estendido à dimensão governamental. Ainda conforme Büttgen: "é também o poder pastoral que, no curso de 1978, faz o liame entre o estudo da governamentalidade e aquele dos dispositivos de poder. É pela mediação do poder pastoral que a questão geral do poder continua a 
delinear-se por trás da governamentalidade" (BÜTTGEN, p. 2007, p. 1131). Embora estejamos de acordo com a perspectiva que não considera o estudo da governamentalidade um abandono da analítica do poder pensamos que não se pode conceder à análise do dispositivo pastoral uma posição absolutamente singular como pretende Buttgen, no que concerne à passagem de uma analítica do poder aos estudos da governamentalidade. Sem dúvidas, o estudo do pastorado ocupa um lugar de destaque no desenvolvimento do curso de 78, porém, é preciso lembrar que Foucault inicia o curso analisando os dispositivos de segurança que compreendem as técnicas de funcionamento da governamentalidade, e o faz de maneira detalhada, de modo que se fôssemos estabelecer uma junção entre analítica do poder e governamentalidade, ou um momento em que Foucault opera a transição de uma analítica para o campo governamental essa teria sido realizada pela analítica dos dispositivos de segurança. Portanto, se Foucault se ocupa do dispositivo pastoral não é para garantir a utilização da analítica do poder e a continuidade dos seus estudos, mas é o próprio movimento de uma genealogia da governamentalidade que coloca Foucault no rastro do poder pastoral e solicita a analítica do poder.

De todo modo, é inequívoca a atenção dispensada por Foucault em relação ao poder pastoral. $O$ curso se inicia com a indicação de estudos em torno do biopoder e passa para as análises do dispositivo de segurança. Ainda que o tema do biopoder se torne cada vez menos referido no prolongamento do curso ele é integrado à temática mais ampla da história da governamentalidade. Desse modo o recuo aos primeiros séculos de nossa era para o estudo do poder pastoral não corresponde a uma digressão na análise governamental, mas parte essencial de uma história da governamentalidade.

$O$ estudo do poder pastoral marca a preocupação de Foucault em enfocar os problemas políticos na perspectiva genealógica. Assim ao realizar a genealogia da governamentalidade nosso autor realiza uma análise política que passa ao largo das discussões tradicionais sob a ótica das teorias da soberania e das teorias do Estado. Pode-se afirmar que Foucault procura por uma outra matriz para o entendimento da política moderna e é nessa perspectiva que se coloca o poder pastoral que escapa à discussão tradicional grega sobre a democracia. Tendo isso em mente, nos colocamos de acordo com a opinião de Prado Filho: "estamos habituados a reconhecer nossos débitos à tradição política fundada pelos gregos, deixando de perceber a ação de outro tipo de poder que opera entre nós de modo bem mais fino e individualizante - o pastorado" (PRADO FILHO, K. 2012, p. 112).

Por fim, vale ainda mencionar que a genealogia do governo obriga Foucault a um recuo histórico mais acentudo. Se no curso de 78 ele encontra as descontinuidades entre a governamentalidade moderna e a prática do poder pastoral a partir do século III, no curso Du gouvernement des vivants de 1980 o autor encontra formas de governo ligadas à direção da consciência que são anteriores a esta datação e que estão presentes no cristianismo primitivo do século I. O influxo do tema da direção da consciência nas considerações do governo não foi desconsiderado por Foucault que volta a examiná-lo nos cursos Subjectivité et Verité em 1981 e L'hermeneutique du Sujet em 1982, desta vez procurando compreender as relações de governo de si no contexto grego da Antiguidade e em que estas se distinguem das práticas de direção cristãs, tema já assinalado em 1980 com a distinção entre exomolegese e exogorese.

COSTA, Helrison Silva. A analítica do poder pastoral na genealogia das artes de governo em Foucault. Griot : 


\section{Referências}

BÜTTGEN, Philippe. Théologie politique et pouvoir pastoral. In: Cairn. Info. n. 62 , p. 1129-1154, 2007.

CANDIOTTO, César. Foucault e a crítica da verdade. Belo Horizonte: Autêntica Editora, 2010.

CHEV ALIER, Philippe. Foucault et le christianisme. Paris : ENS Éditions, 2011.

CHRULEW, Matthew. Pastoral conter-conducts: religious resistance in Foucault's genealogy of Christianity. In: Critical Research on Religion. .v.2, n.1, p. 55-65, 2014.

DUARTE, André. Foucault e a governamentalidade: genealogia do liberalismo e do Estado Moderno. In: Foucault filosofia \& política. Belo Horizonte: Autêntica Editora, 2013.

FOUCAULT, Michel. Dits et écrits II- 1976-1988. Paris : Gallimard, 2001.

FOUCAULT, Michel. La naissance de la biopolique. Paris : Gallimard/ Seuil, 2004a.

FOUCAULT, Michel. Sécurité, territoire, population. Paris : Gallimard/ Seuil, 2004b.

GORDON, Colin. Governmental rationality: an introduction. In: The Foucault Effect: studies in governmentality. Chicago, p.1-52, 1991.

GOLDER, Ben. Foucault and the genealogy of pastoral power. In: Radical Philosophy Review, p. 157-176, 2007.

MCCALL, Corey. Rituals of conduct and counter-conduct. In: Foucault studies, n.21, p. 721, 2016.

PLATÃO. Oeuvres Completes. Paris: Gallimard, 1950.

PRADO FILHO, Kleber. Michel Foucault: uma história da governamentalidade. Rio de Janeiro: Editora Insular/Editora Achiame, 2006.

PRADO FILHO, Kleber. A política das identidades como pastorado contemporâneo. In: Foucault e o cristianismo. Belo Horizonte: Autêntica Editora, 2012.

ROMAN, Chistopher. The Counter-Conduct of Medieval Hermits. In: Foucault studies, n.21, p. 7-21, 2016.

SAVOIA, Paolo. Foucault's critique of political reason: individualization and totalization. In: Revista de estudios sociales. Bogotá, n. 43, p. 14-22, 2012.

SENELLART, Michel. A crítica da razão governamental em Michel Foucault. Tempo Social; Rev. Social. São Paulo, v. 7, n. 1-2, p.1-14,1995.

SENELLART, Michel. As artes de governar: do regime medieval ao conceito de governo. Tradução de Paulo Neves. São Paulo: Editora 34, 2006.

TAZZIOLI, Martina. Revisiting the Omnes et Singulatim Bond: The Production of Irregular Conducts and the Biopolitics of the Governed. In: Foucault studies, n.21, p. 7-21, 2016.

Autor(a) para correspondência: Helrison Silva Costa, Universidade Federal de Minas Gerais, Faculdade de Filosofia e Ciências Humanas, Avenida Antônio Carlos, 6627, Pampulha, CEP 31270 901, Belo Horizonte - MG, Brasil. hcosta.fil@outlook.com

COSTA, Helrison Silva. A analítica do poder pastoral na genealogia das artes de governo em Foucault. Griot : 